\title{
Pemphigus vulgaris
}

\section{Abdullah Mancy}

\author{
Al-Ramadi Teaching Hospital, Al-Anbar Health Directorate, Ministry of Health, Iraq
}

Corresponding author: Abdullah Mancy, MD, E-mail: abdmancy@yahoo.com

Is an autoimmune bullous disease manifested by erosions of the mucous membranes, usually in the mouth, and multiple bullae on the skin. These bullae are ruptured easily, then covered by crust and heal with hyperpigmentation. It is a disease of the middle age and affects both sexes equally. A suprabasal cleft with intraepithelial acantholysis is revealed on histopathology. The disease is treated with steroids, immunosuppressive and biological agents [1-3]. 45years old man presented with painful oral ulcerations and crusted lesions of the trunk for 2 years. On examination, there were multiple, irregular and superficial erosions of the lips and oral mucosa. On the scalp, a linear crusted lesion was present (Fig. la). Multiple crusted papules and plaques on the trunk were found (Fig. 1b). A punch

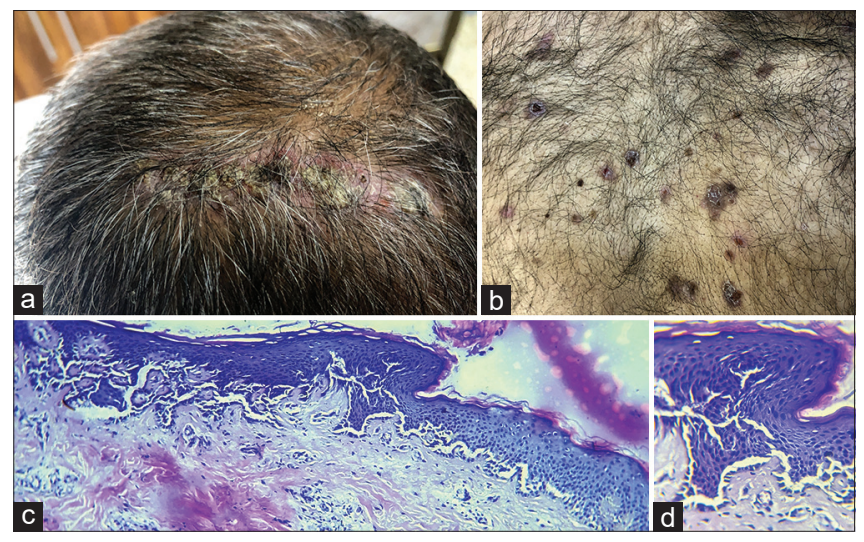

Figure 1: Pemphigus vulgaris. (a)- linear crusted lesion of the scalp. (b)- multiple crusted papules and plaques of the chest. (c)- suprabasal cleft. [H/E stain X10] (d)- suprabasal cleft with tombstone appearance of keratinocytes. [H/E stain X20]. biopsy was taken from the trunk which shows a suprabasal cleft with a tombstone appearance of keratinocytes that is characteristic of pemphigus vulgaris (Figs. lc and ld). Immunofluorescence studies are not available.

\section{Consent}

The examination of the patient was conducted according to the principles of the Declaration of Helsinki.

The authors certify that they have obtained all appropriate patient consent forms, in which the patients gave their consent for images and other clinical information to be included in the journal. The patients understand that their names and initials will not be published and due effort will be made to conceal their identity, but that anonymity cannot be guaranteed.

\section{REFERENCES}

1. James WD, Elston DM, Treat JR, Rosenbach MA, Neuhaus IM. Chronic blistering dermatoses. In Andrews" diseases of the skin. Clinical Dermatology.13 ${ }^{\text {th }}$ ed. Elsevier, 2020, 526- 525.

2. Niyaz A, Viswanath BK. Atypical presentation of pemphigus vulgaris - A rare case report. Our Dermatol Online. 2019;10:88-90.

3. Bay Bay H, Senhaji G, Elloudi S, Douhi Z, Mernissi FZ. Efficacy of Rituximab in the treatment of pemphigus: experience of Moroccan population. Our Dermatol Online. 2019;10:338-340.

Copyright by Abdullah Mancy. This is an open-access article distributed under the terms of the Creative Commons Attribution License, which permits unrestricted use, distribution, and reproduction in any medium, provided the original author and source are credited.

Source of Support: Nil, Conflict of Interest: None declared. 